\title{
Parent Moral Distress From The Perspectives of Mothers With An Infant Previously Hospitalized in The NICU
}

Polychronis Voultsos ( $\sim$ pvoultsos@auth.gr)

Aristotle University of Thessaloniki, University Campus

Maria Deligianni

Aristotle University of Thessaloniki, University Campus

Eftychia Tsamadou

Aristotle University of Thessaloniki, University Campus

\section{Research Article}

Keywords: phenomenon, tolerant, distinct, overlapping, physicians

Posted Date: January 3rd, 2022

DOI: https://doi.org/10.21203/rs.3.rs-1198368/v1

License: (c) (i) This work is licensed under a Creative Commons Attribution 4.0 International License.

Read Full License 


\section{Abstract}

\section{Background}

Given that having an infant in the NICU is a morally stressful event for parents and preterm birth rates are increasing worldwide, parent moral distress is a matter of public health. While moral distress in the clinical context is already a widely explored phenomenon, the parent moral distress still remains a largely under-explored complex phenomenon.

\section{Methods}

This is a prospective qualitative study using semi-structured interviews of seventeen parents (mothers) who previously had an infant in the NICU. The study conducted between February 2021 and August 2021. A thematic analysis of the data was performed.

\section{Results}

While parents with infants in the NICU initially needed for having their decisions respected by physicians, they ultimately shew a tolerant attitude towards benevolent medical paternalism. However, many physician-related factors (i.e. uncertainty, discrepancy of opinion, operational behavior, lack of communicative or empathetic behavior, previous malpractice) facilitate parent moral distress. The important role of the family pediatrician in creating parent moral distress is highlighted. The same holds for family/social environment - related factors. Furthermore, the role of parent's internal factors (especially spiritual/existential core values or beliefs) as well as the role of NICU environment-related factors (such as the image of a long-suffering infant, preventing mothers from providing their own milk for their infants and having a skin-to-skin contact with them) in creating parent moral distress are highlighted. Moral residue no more than mild was found. Moreover, parent moral schisma is emerged as a conceptually distinct from moral distress phenomenon. Last, the findings of this study confirm the relational account of parental moral distress offered by Mooney-Doyle and Ulrich.

\section{Conclusions}

While many findings of the present study are in line with previous studies, our data analysis revealed findings which are little recognized in the available literature. Parents showed tolerant attitudes towards benevolent medical paternalism. No more than mild moral residue has been found. The most relevant categories of variables associated with parent moral distress were a) physician-related (various factors), b) parent-related, c) parent's context (family or broader social)-related, and d) NICU environment-related. Furthermore, parent moral distress and parent moral schisma are conceptualized as conceptually distinct albeit strictly related or overlapping phenomena. The findings of this study support the relational account of parent moral distress.

\section{Background}


The NICU environment is most impactful and inherently stressful for parents. Having an infant in the NICU is a stressful event for them (Chertok et al., 2014 [1]; Segre et al., 2014 [2]; Janvier et al., 2016 [3]; Prentice et al., 2021 [4]). It may cause parents to experience birth trauma and parenting role altering (i.e. experience perceived loss of the parental role) (Roque et al., 2017 [5]). Stress and anxiety are inherent during the infant's hospitalization in the NICU (Rossman et al., 2013) [6]. Infant's hospitalization in the NICU may cause parents to experience a "cluster" of psychological symptoms (psychological distress), individually or together (Loewenstein, 2018) [7]. This cluster often may represent "a combination of depressive, anxiety, trauma and posttraumatic stress symptoms" (Staver et al.,2019) [8]. In the same vein, see Roque et al. (2017) [5]. Parents may experience negative emotions (i.e. guilt) (Roque et al., 2017) [5]. Mooney-Doyle and Ulrich put it best in saying "parental physical and emotional distress is exhibited in many ways, including fatigue, disrupted sleep, caregiving demands, worry, and employment demands" (Mooney-Doyle and Ulrich, 2020) [9]. There is growing body of literature on mental health of parents with an infant in the NICU (i.e. Lasiuk, Comeau, \& Newburn-Cook, 2013 [10]; Hagen, Iversen, \& Svindseth, 2016 [11]; Spinelli et al., 2016 [12]; Roque et al., 2017 [5]; Staver et al., 2019 [8]; Mooney-Doyle and Ulrich, 2020 [9]).

Negative emotions in the context of the NICUs may result from moral distress. Moral distress is prevalent in the NICU that is a hi-tech and stressful setting and confronts morally challenging situations on a regular basis. Moral distress is far more prevalent in the clinical context than even the current literature describes. It is stated that it transcends healthcare professionals and may affect the family (Mills and Cortezzo, 2020) [13]. Moral dilemmas in neonatal critical care may cause both neonatologists and parents to experience moral distress. Parent moral distress is a phenomenon that involves medically complex decision-making and affects population of parents across the world. The hospitalization of an infant in the NICU cause their parents to feel moral emotional tension or strain (Wigert, Dellenmark and Bry, 2013) [14]. The distinct concept moral distress in the clinical context was first defined by Jameton in 1984 as "the psychological distress of being in a situation in which one is constrained from acting on what one knows to be right" (Jameton, 1984 [15]; Jameton, 1992 [16]). Note, however, that moral distress can be conceived not only in the strict sense of the term, but also in the broad sense of the term.

In the strictly defined moral distress (according to the initial/older definition), the parents may feel constrained in pursuing what they believe to be the right course of action in curing their child's illness because of external (i.e. institutional or financial) or internal constraints. The parents may feel constrained from deciding or acting on their personal morality, resulting in compromising their moral integrity. In the broadly defined moral distress (according to the later / more recent definition), the parents feel that their actions or decisions conflict with their core values and deeply held beliefs, resulting in them experiencing a state of mental discomfort, anguish or anxiety. The concept of constraint is central to the original (strict) definition moral distress whereas the concept of uncertainty is central to the newer (broader) definition moral distress (Fourie, 2017) [17]. In neonatology there are many moral dilemmas in a context of extreme uncertainty: 1) End-Of-Life-Care and Palliative Care, 2) Medical Utility and Futility., and 3) Periviability, and 4) Conflict and Disagreement. (Mills and Cortezzo, 2020) [13]. Note however that futility is a term relative to the desired beneficial outcomes. Swetz et al. put it best in saying "the 
quantitative and qualitative aspects of futility are often challenging for clinicians to parse out because these aspects rely on value judgments on the quality of life." It is to be noted that "quality of life is inherently personal" [18].

Moral distress arose from parents' involvement in a situation they perceive as morally questionable. Given the so-called "grey zone" or "zone of parental discretion" in infant's treatment decisions, parents who are most commonly involved in their infant's healthcare, and often are the key decision-makers regarding their infant's healthcare (McDougall et al., 2018 [19]; Mills and Cortezzo, 2020 [13]; Osborne, Fish and Voos, 2020 [20]). At any rate, both constraints and uncertainty should be regarded as being at the core of parent moral distress. parent moral distress Mooney-Doyle and Ulrich put it best in saying "moral distress involves the perception one failed, due to internal and external constraints, to behave in the morally right way or compromised one's own moral integrity or values (provoking intense self-directed negative emotions)" [9]. This account of moral distress has been adopted for the purposes of this study.

Furthermore, Foe and al. highlighted and took a step further in exploring two concepts which were not well-defined and fully understood yet: parents' moral distress in the NICU and what they call "moral schisma" [21]. In Foe et al.'s study, moral distress is strictly conceptualized (according to the Jameton's original definition of the term) and on that basis the authors drew a line of distinction between moral distress and moral schisma. However, when moral distress is conceptualized in the broad sense of the term (later definition), the line of distinction between moral distress and moral schisma becomes blurred. Moral schisma (as conceived by Foe et al.) might be regarded as being encompassed in the concept of moral distress (broadly understood).

Moral distress may cause parents with an infant in the NICU to feel mixed negative self-directed emotions (especially regarding their role as parents), experience distress related to their everyday life, and have negative attitudes towards their relationships (i.e. work-related, family, social). (Campbell, Ulrich and Grady, 2006 [22]; Mooney-Doyle and Ulrich, 2020 [9]). Mothers with an infant in the NICU have reported experiences of negative emotions such as frustration and mourning, fears, angry and shame) which however they oppressed to be viewed as "good mothers" (Sydnor-Greenberg \& Dokken, 2000 [23]; Lasiuk et al., 2013 [10]).

Importantly, Mooney-Doyle and Ulrich recently offered an integrated account of parent moral distress. The authors defended an updated three-dimensional relational definition of the phenomenon. They stated: "Three dimensions emerged from the literature surrounding parent moral distress: an intrapersonal dimension, an interpersonal dimension, and a spiritual/existential dimension" (Mooney-Doyle and Ulrich, 2020) [9]. This account of parent moral distress remains to be further explored and confirmed by empirical research.

This study attempted to add to the understanding of the complex but important phenomenon of parent moral distress in neonatal intensive care unit clinical context and ultimately, contribute to addressing the relative literature gaps. Given that preterm birth rates are increasing worldwide (Blencowe et al., 2012 [24]; Liu et al., 2012 [25]), having an infant in the NICU is a morally stressful event for parents and parent 
moral distress creates negative self-directed emotions, we all need to understand that in the context of neonatal intensive care parent moral distress is a matter of public health. While moral distress in the clinical context is already a widely explored phenomenon, the concept and the dimensions of parent moral distress in the context of neonatal intensive care is a topic which still remains largely underexplored despite the fact that it is a complex phenomenon that has gained increased attention across disciplines (Mooney-Doyle and Ulrich, 2020) [9]. While there is growing body of literature on mental health of parents with an infant in the NICU and moral distress experienced by health professionals within NICUs, there is limited empirical research about the nature and degree of parents' moral distress experienced within the NICU (Prentice et al., 2016) [26].

\section{Research Questions}

The overarching question delineating the focus of this study was the following:

What is parent moral distress (broadly understood) from the perspectives of mothers with an infant who has been hospitalized in the NICU in the last three years before the interview?

The secondary research questions were the following:

a) What is the nature of the parent moral distress (broadly understood) in the neonatal intensive care context?

b) What are the factors that determine the parent moral distress (broadly understood) from the perspectives of mothers with an infant previously hospitalized in the NICU?

c) What are the parents' perceived experiences or manifestations that might reflect what the literature attempted to describe as parent "moral schisma" in the neonatal intensive care context?

\section{Study Design}

The present work was a prospective qualitative research study based on in-depth interviews with parents with an infant in the NICU in the recent past. This qualitative descriptive study was conducted from February 2021 to August 2021. Thematic analysis (a widely used qualitative research technique) was selected as the methodological orientation to underpin the study.

\section{Participants}

\section{Sampling and data collection}

Purposive sampling was used according to the eligibility criteria set out below.

A total of 20 parents (biological mothers) were initially recruited by the interviewer (MD). Seventeen mothers agreed to be interviewed, whereas 3 parents chose to not participate. None of the patients 
initially agreed to participate and then changed their mind and declined participation.

The selected study participants $(\mathrm{N}=17)$ were mothers with an infant in the NICU before the time of the interview. They were diverse in terms of age, place of residence, and educational background. The age of the participants ranged from 29 to 48 years, with the majority being under 40 years old. The mean (standard deviation, $S D)$ age of the participants was $36(S D=5,5)$ years. All participants were adults and Greek citizens resided in urban areas in the Northern Greece. Furthermore, they were diverse in terms of their infants' gender, gestational age, length of stay in the NICU and timespan between interviews and their infants' birth. The average gestational age of the infants was 28,64 weeks. The minimum infant gestational age was 26 weeks, with the gestational age of only one infant being 25 weeks. A 25 weeks old infant died in a short period of time after being discharged from the NICU. The length of stay in the NICU ranged from 30 to 120 days. The average NICU length of stay was 73,06 days (in the exception of an infant who stayed in the NICU for a short time and then died at home). The average birth weight of the infants was $961,17 \mathrm{gr}$. All the infants were alive at the time of interviews in the exception of one only infant who died in a short period of time after being discharged from the hospital.

The timespan between birth and interview ranged from 17 months to 3 years, with only two infant being 8 months and 35 days old respectively, and an infant having died in a short period of time after the discharge from the NICU. The participant characteristics are presented analytically in Table 1. 
Table 1

Participant characteristics

\begin{tabular}{|c|c|c|c|c|c|c|c|}
\hline Participant & $\begin{array}{l}\text { Participant } \\
\text { age }\end{array}$ & $\begin{array}{l}\text { Infant } \\
\text { gender }\end{array}$ & $\begin{array}{l}\text { Gestational } \\
\text { age } \\
\text { (in weeks) }\end{array}$ & $\begin{array}{l}\text { Birth } \\
\text { weight } \\
\text { (in } \\
\text { grammar) }\end{array}$ & $\begin{array}{l}\text { Length } \\
\text { of stay } \\
\text { in the } \\
\text { NICU (in } \\
\text { days) }\end{array}$ & $\begin{array}{l}\text { Age of } \\
\text { infant at } \\
\text { the time } \\
\text { of } \\
\text { interview }\end{array}$ & $\begin{array}{l}\text { Other } \\
\text { children }\end{array}$ \\
\hline P1 & 36 & female & 26 & 850 & 75 & $\begin{array}{l}18 \\
\text { months }\end{array}$ & $\begin{array}{l}\text { "It is } \\
\text { the } 2 \text { nd } \\
\text { child" }\end{array}$ \\
\hline P2 & 30 & female & 27 & 800 & 100 & $\begin{array}{l}22 \\
\text { months }\end{array}$ & $\begin{array}{l}\text { "It is } \\
\text { the } 1 \text { st } \\
\text { child" }\end{array}$ \\
\hline P3 & 32 & male & 29 & 1040 & 35 & $\begin{array}{l}28 \\
\text { months }\end{array}$ & $\begin{array}{l}\text { "It is } \\
\text { the } 1 \text { st } \\
\text { child" }\end{array}$ \\
\hline P4 & 29 & male & 28 & 740 & 73 & $\begin{array}{l}19 \\
\text { months }\end{array}$ & $\begin{array}{l}\text { "It is } \\
\text { the } 1 \mathrm{st} \\
\text { child" }\end{array}$ \\
\hline P5 & 30 & female & 28 & 940 & 70 & $\begin{array}{l}17 \\
\text { months }\end{array}$ & $\begin{array}{l}\text { "It is } \\
\text { the } 2 \text { nd } \\
\text { child" }\end{array}$ \\
\hline P6 & 35 & female & 30 & 1100 & 90 & $\begin{array}{l}21 \\
\text { months }\end{array}$ & $\begin{array}{l}\text { "It is } \\
\text { the } 2 \text { nd } \\
\text { child" }\end{array}$ \\
\hline P7 & 33 & male & 29 & 1000 & 45 & 2,5 years & $\begin{array}{l}\text { "It is } \\
\text { the } 1 \text { st } \\
\text { child" }\end{array}$ \\
\hline P8 & 33 & male & 27 & 710 & 93 & 3 years & $\begin{array}{l}\text { "It is } \\
\text { the } 2 \text { nd } \\
\text { child" }\end{array}$ \\
\hline P9 & 36 & male & 26 & 900 & 120 & 2,5 years & $\begin{array}{l}\text { "It is } \\
\text { the } 1 \text { st } \\
\text { child" }\end{array}$ \\
\hline P10 & 48 & female & 28 & 1000 & 120 & 3 years & $\begin{array}{l}\text { "It is } \\
\text { the } 1 \text { st } \\
\text { child" }\end{array}$ \\
\hline P11 & 36 & male & 33 & 1,320 & 30 & 3 years & $\begin{array}{l}\text { "It is } \\
\text { the } 4 \text { th } \\
\text { child" }\end{array}$ \\
\hline P12 & 43 & female & 28 & 880 & 77 & $\begin{array}{l}2 \\
\text { years }\end{array}$ & $\begin{array}{l}\text { "It is } \\
\text { the 2nd } \\
\text { child" }\end{array}$ \\
\hline
\end{tabular}




\begin{tabular}{|c|c|c|c|c|c|c|c|}
\hline Participant & $\begin{array}{l}\text { Participant } \\
\text { age }\end{array}$ & $\begin{array}{l}\text { Infant } \\
\text { gender }\end{array}$ & $\begin{array}{l}\text { Gestational } \\
\text { age } \\
\text { (in weeks) }\end{array}$ & $\begin{array}{l}\text { Birth } \\
\text { weight } \\
\text { (in } \\
\text { grammar) }\end{array}$ & $\begin{array}{l}\text { Length } \\
\text { of stay } \\
\text { in the } \\
\text { NICU (in } \\
\text { days) }\end{array}$ & $\begin{array}{l}\text { Age of } \\
\text { infant at } \\
\text { the time } \\
\text { of } \\
\text { interview }\end{array}$ & $\begin{array}{l}\text { Other } \\
\text { children }\end{array}$ \\
\hline $\mathrm{P} 13$ & 35 & female & 30 & 920 & 120 & 1,5 years & $\begin{array}{l}\text { "It is } \\
\text { the } 1 \text { st } \\
\text { child" }\end{array}$ \\
\hline P14 & 39 & female & 27 & 820 & 60 & $\begin{array}{l}22 \\
\text { months }\end{array}$ & $\begin{array}{l}\text { "It is } \\
\text { the } 2 \text { nd } \\
\text { child" }\end{array}$ \\
\hline P15 & 32 & male & 25 & 640 & died & & $\begin{array}{l}\text { "It was } \\
\text { the } 1 \text { st } \\
\text { child" }\end{array}$ \\
\hline P16 & 35 & female & 32 & 1400 & 31 & 8 months & $\begin{array}{l}\text { "It is } \\
\text { the 2nd } \\
\text { child" }\end{array}$ \\
\hline P17 & 47 & female & 34 & 1280 & 30 & 35 days & $\begin{array}{l}\text { "It is } \\
\text { the } 1 \text { st } \\
\text { child" }\end{array}$ \\
\hline
\end{tabular}

\section{The inclusion criteria}

The inclusion criteria for participation in the study were (1) being able to use and communicate in Greek language, (2) being parent of a premature infant who were hospitalized (at the time of the interview or in the recent past) in the NICU for at least a week, Furthermore, (3) the children previously hospitalized in the NICU should be no older than three years, so that their parents still have vivid memories of their infant being hospitalized in the NICU, and (4) At least one partner in a couple should be available for interview..

\section{The exclusion criteria}

The exclusion criteria for participation in the study were (1) inability to use and communicate in Greek language inability, (2) recent death of the hospitalized in the NICU infant (occurred within the past year), (3) recent death of another child in the family (occurred within the past year), or (4) infant currently hospitalized in the NICU. The reason for the (2),(3) and (4) criteria was that bereavement reactions to a child's death or actual distress (moral or psychological) might have a profoundly negative impact on participants' narratives. The in-hindsight narratives might be affected by moral residue.

\section{Interviews}

Data were collected through in-depth individual semi-structured interviews. Interviews were conducted one on one between February 2021 and August 2021 and lasted between 42 and 56 min. The mean length of the interviews was 48 min. Interviews were audio recorded and transcribed verbatim into written Greek. 
All interviews were carried out in person by the interviewer (MD), a specialist in paediatrics possessing a Master of Medical Ethics and experienced in qualitative interviewing. Relevant field notes were written before and after the interviews by the interviewer to help produce a comprehensive set of insightful findings.

The interview language was Greek. Interviews were held at interviewees' preferred time in quiet and neutral places of the participant's choice with a comfortable environment. All of the participants reported that they made joint decisions with their husbands about their infants' care. In most interviews the mothers were speaking on behalf of their husbands and themselves.

\section{The interview guide}

The interview guide was developed based on a review of the relevant literature and then, as a first step, pilot tested. The guide was slightly refined based on the initial results from a few interviews to help the participants to better understand the specific issues being asked about in the questions. As new topics emerged from the preliminary data analysis of the initial few interviews, in subsequent interviews these topics became the subject of additional questions, which were added to the interview guide. Moreover, we next developed an informal grouping of topics and questions that the interviewer could ask in different ways for different participants. To gain a deep and comprehensive understanding of the underlying phenomena, the interview guide covered a number of topics to capture a wide range of the participants' lived experiences. The interviews were focused, among other things, on elucidating the reasons why parents with one (at least) infant in the NICU felt to suffer from moral anguish, their experiences of facing moral dilemmas and being involved in share decision making process. Moreover, the interviews included questions about the parents' perceptions of right and most appropriate medical treatment, as well as questions about their view of their relationships with the physicians and other health professionals in the NICU. Study participants were also asked about difficulties complying with the treatment offered. The interviews started by guide questions such as the following:

a) Have you ever asked to express your opinion about the treatment of your infant in the NICU or were involved in parent-physician shared decision making? Might this cause you to experience feeling of suffering from anguish? Please, describe to me why and describe to me what were your experiences in detail. b) Please describe to me any significant difficulty you have had dealing with your problems and making a clear judgement about what course of action should be taken. c) Have you ever felt concerned about the treatment provided to your infant in the NICU or torn between adopting A and B attitude towards the treatment provided to your infant in the NICU? If yes, please describe to me what were your experiences in detail. d) Have you ever been felt to be constrained from acting on what you knew to be right? If yes, what do you believe were the main reasons why you had to comply with the treatment provided? e) Have you ever had a disagreement or been felt to be in a bad relationship between you and the NICU personnel? Please, tell me about your experience. f) Have you ever asked to express your opinion about the treatment of your infant in the NICU or were involved in parent-physician shared decision making? Might this cause you to experience feeling of suffering from anguish? Please, describe to me why and describe to me what were your experiences in detail. g) Have you ever felt concerned 
about the treatment provided to your infant in the NICU or torn between adopting A and B attitude towards the treatment provided to your infant in the NICU? If yes, please describe to me what were your experiences in detail. h) Have you ever been felt to be constrained from acting on what you knew to be right? If yes, what do you believe were the main reasons why you had to comply with the treatment provided?

\section{The interviewer - interviewees relationship.}

Although the researcher had a clinical background, she assumed the researcher role for the interviews.

The researcher contacted the parents and spent time with them beforehand to gain their trust and ensure trustworthiness in the study. The interviewer answered any questions that the parents asked. In a preliminary stage, interviewees were asked questions regarding their demographics and were induced to get into insightful discussions on the status and complications of their pregnancy and birth of the baby who has been hospitalized in the NICU. The participants were encouraged to expand upon the examined topics. They were asked broad questions and encouraged to respond in a conversational way to express themselves. Participants were encouraged to expand upon issues they considered most relevant and speak as freely as possible about them. They were encouraged to elaborate on their initial responses to the questions and expand upon issues they considered most relevant.

Furthermore, the researcher took great care to make the interviews feel more like a conversation and less like an interrogation from the parents' perspective. Reflexive thinking was applied throughout the research process to reduce unintentional personal bias. The interviewer did not hold any strong views about medical ethics and remained neutral on issues that were discussed with the parents. As phenomenological researchers, we were interested in describing the participants' experiences while maintaining an unreflective and effortless (normal) attitude. In this perspective, the interviewer made every effort not to ask leading questions and not to interrupt the interviewee while speaking or to disturb the interviewee while remaining silent. The interviewer was not speaking too much, thus giving enough time to interviewees. We attempted to eliminate hindsight bias (which might skew the participants' judgment) by prompting participants to put great effort into recovering even the weak memory traces.

Data collection ceased only when data saturation was reached, a point where no additional information was obtained from further interviews. In this perspective, Data collection continued until after 14 interviews. Three more interviews were also conducted to ensure data saturation.

\section{Data analysis}

Thematic analysis was the qualitative research technique selected as the methodological orientation to underpin the study.

All the co-authors contributed to the analysis from their respective points of view as a bioethicist, psychiatrist, or pediatrician. They engaged with one another to limit research bias. 
The researchers made every effort to ensure the validity and reliability of the study according to Gibbs (2007) [27]. Moreover, the researchers paid a considerable role in using strategies to minimize reflexivity throughout the project. In this perspective, throughout the interview data analysis, they drew upon their own clinical experiences in a reflexive manner. Furthermore, credibility was supported using maximum variance in participant selection. Moreover, transferability was achieved via the provision of a rich description of the data collection, analysis processes and findings. So, the readers are allowed to match the findings with their contexts.

After each interview was transcribed word for word, in the first step, each interview transcript was read through carefully and repeatedly to obtain a good overall sense of the whole transcript and an impression of its content (Burnard et al., 2008) [28]. In the second step, units expressing meaning were identified in each interview transcript, and units similar in meaning were coded. The researchers constantly compared data to ensure that the codes were used consistently (Patton, 2002) [29]. In the third step, codes similar in meaning were grouped into subcategories. In the fourth step, subcategories compared with each other and the latent data content were condensed into broader categories. The final categories were refined by all authors by ensuring a clear difference between categories and subcategories. The lists of categories were grouped under higher-order headings. The categories were grouped into prevailing themes as the final product of the analysis. Disagreements between the authors that arose during the data analysis were easily addressed with re-examination of the data and further discussion.

Data analysis was carried out using NVivo qualitative data analysis software version 9 released in 2010.

\section{Ethical Considerations}

Written informed consent was obtained from participants. If parents with an infant in the NICU were willing to participate, they were given adequate information about the design, purpose, nature and confidentiality of the study, including that participation was voluntary and that consent could be withdrawn at any time during the course of the study without giving any reason and without reprisal. Great weight was placed on the importance of maintaining anonymity and confidentiality. Anonymity and confidentiality were maintained throughout the study. Interview data were anonymized during transcription. To preserve participants' anonymity, no names are used in this paper. In order to preserve their anonymity, numbers (e.g. P1) are used in this paper. The interviews were registered and stored in a strictly confidential fashion. The study and consent procedure were approved by the Ethics Committee affiliated with Aristotle University of Thessaloniki, Faculty of Health Sciences, School of Medicine (Decision Number: 2.437/24-11-20).

\section{Results}

Seventeen interviews were conducted in the framework of the study, focusing on the parents' moral experiences due to their involvement in distressing aspects of having an infant in the NICU. Below, we present the results that emerged from our interview data analysis to answer our research questions 
related to the phenomenon of parent moral distress in the NICU context. The below presented themes and subthemes are the findings retrieved from the interview data analysis and might serve as a starting point for further theoretical and empirical research on the topic parent moral distress in the neonatal clinical context. The themes and sub-themes presented below are regarding parents attitude towards beneficent medical paternalism, reasons behind parent moral stress, moral residue, and the concept moral schisma. The most relevant categories of variables associated with parent moral distress were a) physician-related (various factors), b) parent-related, c) parent's context (family or broader social)-related, and d) NICU environment-related.

We identified a number of factors that are involved in parent moral distress in the NICU context. The distinction between parent moral distress and parent moral schisma, and the relational account of parent moral distress might be regarded as overarching themes that emerged from the data analysis, which might contribute to moving forward the discussion surrounding the topic of interest in this study.

We present a variety of interview quotes to illustrate different themes and subthemes that reflect different dimensions of the phenomenon of interest.

Some participants declared (more or less intensely) their concerns about whether the right whole care plan was recommended or provided, with other participants expressing their concerns about only a single medical intervention (diagnostic such as CT scan or therapeutic such as blood transfusion). Furthermore, moral distress in the context of neonate intensive care may be related to the NICU environment. Moreover, participants were in denial about the withdrawal of their neonates' life-sustaining treatment (labelled by neonatologists as futile). Last, in cases of physicians' uncertainties or inability to make clear medical decisions, parents were at loss while being faced with inextricable dilemmas which caused them to experience a strong internal conflict (Table 2).

Table 2

Situations involving parent moral distress or schisma

\begin{tabular}{|lll|}
\hline Morally stressful situation & $\begin{array}{l}\text { Number of } \\
\text { participants }\end{array}$ & Participants \\
\hline Parent concerns about the whole care plan & 6 & $\begin{array}{l}\text { P2, P3, P7, P10, } \\
\text { P11, P12 }\end{array}$ \\
\hline $\begin{array}{l}\text { Parent concerns about only a single diagnostic procedure or } \\
\text { therapeutic intervention }\end{array}$ & 4 & P1, P2, P6, P9 \\
\hline Moral stressors related to the NICU environment & 6 & $\begin{array}{l}\text { P5, P9, P10, P12, } \\
\text { P14, P17 }\end{array}$ \\
\hline Medical futility & 2 & P14, P15 \\
\hline Medical uncertainties & 3 & P4, P8, P16 \\
\hline Inextricable (or perceived as inextricable) moral dilemmas & 3 & P4, P9, P13 \\
\hline
\end{tabular}


We have identified a number of reasons behind parent moral stress. The most relevant categories of variables associated with parent moral distress were a) physician-related (various factors), b) parentrelated, c) parent's context (family or broader social)-related, and d) NICU environment-related. Furthermore, moral schisma was emerged as a distinct concept. Moreover, a mild moral residue has been identified among participants in this study. In addition, the findings of this study further confirm the relational account of parent moral distress.

In the case of parents with concerns about whether the right medical care plan or intervention was recommended or provided, disagreements between parents and physicians were due to discrepancies in knowledge and expectations. Nevertheless, in the case of physicians who negotiate their judgment that conditions of medical futility are met, disagreements between parents and physicians were due to discrepancies in values and beliefs. Note that in most cases of parents with concerns about only a single medical intervention, they did not share their disagreements with their infant's health providers. These finding are in line with the currently available literature [4] as presented below in the Discussion section.

The parents' difficulty to determine what the infant's best interest is, made them give their consent despite the concerns they have about whether the right treatment was recommended (or provided) or despite their involvement in situations that are perceived as extremely morally questionable.

\section{Parents' tolerant attitude towards beneficent medical paternalism}

\section{Beneficent paternalism (soft)}

The vast majority of participants reported that the physicians made decisions for their infants based on "I know what is best for your baby". In other words, they described beneficent medical paternalism that discounts the so-called "parental discretion zone".

Physicians' firm conviction about the course of action to be taken (despite the uncertainty in the context of neonatology) caused parents to remain voiceless in the face of the severity of the situation. In reality, neonatologists had a paternalistic attitude, with paternalism being conceived as soft paternalism. Note moreover, that all the participants (in the exception of those being in denial of medical futility) showed a tolerant attitude towards the physicians' paternalistic behavior.

The participant P2 expressed her strong concerns as to whether intubation should be performed on her infant. She said,

The neonatologists never asked for my consent to proceed with intubating my baby. He just firmly informed me that my baby was about to be intubated...then I stopped talking. The baby was under their responsibility, they were in charge of her. So he took her and proceeded with intubation just like that no further questions asked. 
In the same vein the participant P9 said,

At some point when they had a blood transfusion I think it's called, I was really scared they might infect my baby. They totally ignored my concerns then. They just informed me that due to the child developing severe anemia they had to proceed with the blood transfusion. So I was forced not to say anything, I just accepted the situation.

Furthermore, the participant P9 said,

They informed us every day...there were not any points where we disagreed with the doctors but equally they never asked for our opinion or consent. They did what they considered was the right thing to do.

\section{Indirect coercion: leaving parents with no choice}

Some physicians provided adequate information in order to convince parents to accept the recommended medical intervention and believe in its appropriateness. However, parents who were not persuaded were left with no choice. Physicians made parents responsible for their infant's life or health. They adopted a quasi-coercive attitude as a last resort in order to save the infant's life put under imminent risk. The physicians gave a presentation of the crude reality to the ignorant, inexpert and inexperienced parents. If the goal of obtaining parent's persuasion was unattainable, physicians narrowed down the parents' options and made them look at the available data to guide their choice in the current circumstances. They left parents with no or little choice. Physicians put the parents' (who lack medical knowledge) in front of a life-threatening dilemma: "give your consent or the baby will die". This can be regarded as an ethically justifiable (soft) paternalism in deviation from the specific consent rule. The pressure that arose from the particular circumstances (as presented by the physicians) created a sense of depression that compelled the parents to give their "consent" in terms of just saying an OK! while having a lot of reservations.

The participant P2 said,

He took me to his office. There he started explaining his point of view, why it was necessary to proceed in that way. And at the end he said pretty firmly that if the baby died it would have been my fault and that I should not ask them why. That was it! There is nothing else he could do he said. His words put me in a very difficult position and I remained silent. How could a mother respond to such a statement? My heart was hurting when I agreed to it and this is a moment I will never forget. It was a proper trauma for me, proper trauma. I don't think I have taken a more important decision in my life. The burden of this decision affected me mentally. I could not cope for a long time.

In the same vein, the participant P3 said,

The neontologists kept saying: "What are you talking about madam? We can't do this. Your baby is in danger. He might get severe apnea, with oxygen stop flowing into his heart and brain. If this happens, what baby are you expecting to get back? And then you will blame us for this". What could be a mother's 
response to that? I panicked and it felt like I had to consent. Given the doctors were telling that we had to do it \& we had no other option, so yes I gave my consent.

Providing detailed information while communicating effectively induced almost all the participants to come around and leave behind their concerns about or objections to the appropriateness of a medical treatment or a medical decision made for their infant. In situations where for parents there was no escaping from making a difficult healthcare decision for their infants, physicians who attempted to achieve an effective communication and provision of information to parents finally persuaded them to give their autonomous informed consent

The participant P3 said,

Yes I disagreed. Indeed I disagreed. I disagreed about everything I described to you. Nevertheless I was convinced.

In the same vein, the participant P1 said,

They were adamant. They took responsibility for everything. They had their way of convincing you.

\section{Ultimately, parents showed respect for physicians' knowledge and professional experience}

The participants' thought that physicians "know better" than themselves was always at the back of their mind. Our interview data analysis showed that at the back of their minds, all of the participants doubtless realized that perhaps they may be wrong and that the diagnostic or therapeutic medical interventions that the physicians believe would improve the infant's outcome may be the right action to be taken against the illness of their babies. While parents expressed their concerns as to whether the medical intervention recommended or provided to their infant is the appropriate, they felt they could not bear the full responsibility for denying it to the very end. It is to be highlighted that while many participants had moral concerns about whether the treatment provided is the appropriate, none of the participants requested the premature discharge of their infant being hospitalized in the NICU. None of the participants dared to take on such a responsibility for their babies.

The interview analysis allowed us to understand that participants were aware of their ignorance and inexperience in the field of neonatology. In this perspective, most participants who raised internal concerns about whether the treatment recommended or provided was the appropriate for their infant, they did not share their concerns or expressed their concerns in a mild way. All the participants who had concerns about whether the treatment recommended or provided was the appropriate, they finally came around and said an OK.

The participants P3 and P10 stubbornly opposed the physician's views. While physicians strongly recommended their infants to get intubated, the participants stubbornly refused this medical intervention for their infant. However, they finally came around and said an OK. 
The participant P10 said,

Again she was put in ICU [intubated] because she had hypoxia they told me. I was not in agreement with that approach. Of course I don't consider myself a doctor hence I could not say anything further. I didn't know how it would perceived. Every time I expressed my opinion I was told that they knew better and that they would do the best they could for my child. Obviously I didn't share that view, I disagreed but I could not do something about it. This was indeed their responsibility \& they were qualified to do this. I could not take such responsibility for my own child.

Furthermore, while the participant P1 had trust in physicians and had no concerns about the whole care plan, she had strong concerns (internal rather than shared and expressed) about performing a CT scan on her infant because of the radiation risk associated with CT scan. However, she finally said an OK. She said,

I only disagreed with them having to put the child through a CT scan. Can you imagine they did two CT scans to my child. I was extremely frustrated and ready to kick off. In the end I could not do anything to change this. They were adamant to proceed. In the end they put my child through MRIs, CT scans anything they wanted. Whatever they deemed that had to be done. Surely I am not a doctor... I did trust them. They took control so if something had to be done I went along with this. I had to put aside all my doubts and concerns and let them do what they had to.

In the same vein the participant P9 was stubbornly opposed to administering a blood transfusion to her infant because of the risk for transfusion-transmitted infections. However, she finally said an OK. In the words of the participant,

...I was forced not to say anything and keep my thoughts to myself.

The participant P12 who is a General Practitioner, initially expressed her concerns intensively. However, she finally came around. As a physician she could understand that the context of neonatal intensive care is a context of inherent uncertainty, where great experience is necessary to achieve a reliable decisionmaking process. She said,

I insisted that they need to operate his intestine, given a part was not working properly... however they would not change their protocol. This was very upsetting for me you see...I was really upset. I appreciated that they had seen a lot of similar cases and hence they were trying to re-assure me that everything would get back to normal but I kept feeling that something was not right. I must admit that at numerous times I thought that the treatment plan was not the right one. In the end, I discussed it with my husband and we sought the opinion of another colleague of mine from overseas... he also didn't provide a straight view and sat on the fence... I was still unconvinced...

\section{Physician-related factors that can play a crucial role as reason behind parent moral distress}


In the present study, the data analysis revealed a number of factors which can serve as resources of parent moral distress.

\section{Physician uncertainty about the right action to be taken}

A situation indicating heightened medical uncertainty can serve as an antecedent to moral distress or schisma. The participant P16 emphasized her moral strain that arose from physicians' uncertainty as to whether the use of CPAP would be effective in managing respiratory failure in her infant or an intubation should be performed. She said,

Even the doctors didn't come across confident and that made me even more anxious as I felt that they were not sure either about what had to be done.

In the case of the participant P13 the physicians expressed uncertainty as to whether her infant (perceived by mistake as severely ill) might or should be transferred to a remote though much more specialized setting,

In the case of the participant P8 medical uncertainties escalated into disagreement between the physicians. In the words of the participant,

I was not impressed with the fact that at some point the neonatologists had a disagreement amongst them as to whether they should put a central intravenous catheter to the baby. And it was at that point that I lost my mind and doubted everything.

In the case of the participant P9 the physicians were at a loss as to which course of treatment should be followed.

\section{Physicians' professional commitment and effort to optimizing the infant's outcome}

Almost all of the participants recognized the physician fatigue and the NICU environment as a hard and demanding (physically and psychologically) workplace. The vast majority of the participants recognized the NICU physicians' keenness to go above and beyond the call of duty and their fervent desire to optimize the infant's outcome. Furthermore, the vast majority of the participants recognized that the NICU physicians felt like wanting to provide adequate information and effectively communicate with the parents. Parent's strong reservations about physicians' professional commitment have been reported as factors that can be driving forces behind moral distress. According to participants, professional operational way of behaving adopted by physicians who did not behave in an empathic way and did not do their best for optimizing the infant's outcomes could serve as a significant facilitator of moral distress (broadly understood). Physicians who act or behave as real healers (doing their utmost for optimizing the infant's outcome) rather than operators fulfilling their duties under the law gained the parents' trust.

The participant P6 said, 
Afterwards they asked for my consent to proceed with a blood transfusion if they had to. They explained to me that they would only proceed if it was absolutely necessary. They re-assured me that the blood to be used was checked and that I should not be worried for such things. However, I could sense that they genuinely cared for my child and that they were doing their best in the circumstances and this was helping me place more trust in them and keep a positive outlook about what they were doing.

In the same vein the participant P3 said,

...they kept informed all the time. It was obvious they were not just completing a task in a mechanic like fashion, they really put a lot of effort and energy into it. I could sense their effort to look after my baby and I felt somehow relived. I kept telling myself they were doing the right thing... they don't just do their job. Generally speaking, I felt that the communication with the doctors was good and I could sense they deeply cared. They are just not doing something for the shake of doing it right?

The image of physicians as perceived by parents can serve as barrier or facilitator of establishing a trusting relationship parents and physicians. This was a recurrent finding throughout the participants' narratives.

The participant P8 said,

... we could see how they were running around sweating excessively...

The participant P5 observed the physicians' effort to optimize the infant's outcome crossing their face. In the words of the participant,

I could see it in their eyes and also in the way they behaved throughout the process that they were really trying.

In the same vein the participant P3 declared,

... I could sense their effort to look after my baby and I felt somehow relieved. I kept telling myself they were doing the right thing...they don't just do their job. Generally speaking, I felt that the communication with the doctors was good and I could sense they deeply cared. They are just not doing something for the shake of doing right?

Two participants complained that the physician behavior gave them the impression that their severely ill infants have already inconvenienced the NICU because of their poor prognosis. As parents always strive to make the best decision for their infants, this behavior caused parents to feel severe psychological distress and moral discomfort.

The participant P13 stated,

The fact that was difficult for me to comprehend in that unit was that I felt that they somehow wanted to distance themselves from such a case. Such a case seemed to be a burden with a really bad prognosis. 
In the same vein the participant P15 declared,

They seemed they wanted to get done with this baby and that this was a burden to the unit. I didn't feel that way!

\section{Parents' suspicion of healthcare providers}

A participant worried whether the (overwhelmed at work) physician on duty put the infant's life or health at further risk so as to reduce the burden of his workload.

The participant P11 said,

I told them that I didn't want them to intubate him if this was possible. They set him up and left him. However overnight his situation deteriorated and they ended up intubating him. I don't really know if that was the case or they just wanted to be sure hence why they intubated him. After all it was a hard shift...

\section{Previous medical malpractice}

In the case of the participant P13 misdiagnosis undermined her trust in physicians despite the effort of the physicians to make the right diagnosis. Furthermore, the case of the participant P13 suggests that parents who perceived physicians as having successfully dealt a challenging situation with their infant are likely to put their trust in the physicians. She declared,

That's right..there was no heart tumor... I was devastated..i completely lost all my trust for the doctors and said to myself that was it. At the same time however I really relied on the doctors of this unit and decided that whatever they say I would go with..they relieved me from a big concern. So I said to them take her and do whatever you think is right. Afterall you know better.

\section{Discrepancy between physicians' opinions on the course of action to be taken}

From our interview data analysis emerged that the trust the patients placed on NICU physicians was greatly dependent on the agreement or discrepancy between the physicians' opinions on the course of action to be taken against the illness of the infant in the NICU.

The participant P3 said,

I disagreed of course. I disagreed with everything I described to you. Nevertheless and after all of them told me the exact same thing I was convinced. Then I also consulted with my pediatrician who told me "Sofia sounds like this is what needs to happen".

The discrepancy between the opinions of infant's attending neonatologists can be a major antecedent to parent moral distress. The difference of opinions between physicians gives rise to parent concerns about whether it is right to provide a particular treatment and causes parents to feel traumatized. 
The participant P8 said,

I was not impressed with the fact that at some point the neonatologists had a disagreement amongst them as to whether they should put a central intravenous catheter to the baby. And it was at that point that I lost my mind and doubted everything. My husband was really upset... Thankfully both my husband and my best friend were there to support me emotionally and psychologically. I cant forget the pressure I was under in there from feeling unsure about my baby's situation, especially as the neonatologists kept disagreeing amongst them regarding best course of action.

In the same vein, the participant P9 said,

One shift supervisor kept telling me we should wait. Another one during his shift insisted that we needed to proceed with a more aggressive treatment protocol. I felt that even the doctors themselves were not $100 \%$ certain about this.

\section{Unmet parents' communication needs can serve as an antecedent to moral distress or schisma}

Participants were seeking not only effective, but also empathetic communication between health providers and themselves in the NICU context. They had considerable communication needs, which however, might not be met by the NICU staff.

The following interview quote illustrates the parents' needs for better communication with NICU staff. The participant P8 said,

But the one thing that really stressed me out \& made me feel under a lot of pressure was the limited information that I was provided with. We felt that we should have been informed about the situation with sufficient detail and with respect towards our concerns and pain that we had been going through. We could see how tired they would get but despite this we felt that the communication with parents/guardians could be improved.

The following interview quote illustrates the importance of information and good communication between parents and NICU staff. The participant P3 said,

They informed me again and again. I totally understood that they didn't perform their job as cold blooded professionals.. they really tried and fought for it.

Importantly, the participant P2 said,

I am just flagging that the doctors you know have the knowledge and experience and they decide based on this. They approach situations in a more sensible manner. Parents on the other side rely on their instincts, the love they feel for their children. And this is what the physicians need to appreciate and discuss with parents. Invest some time, with empathy and warmth. They need to invest more time in building the communication with the parents/guardians. It is extremely important. I appreciate that their 
job is tough but equally the parents have their own concerns and someone needs to lean over and listen to them. Even if they sound silly at first glance.

Furthermore, the participant P13 said,

I really don't want to judge them ...it's a tough job and you work under a lot of pressure... my point is though that some doctors do seem to take into account \& acknowledge the concerns of the parents, whilst some others behave like cold blooded professionals.

Moreover, the participant P11 said,

I believe that the main reason that led to the uncertainty and confusion was the lack of clear communication and connection with the medical team. Which I think has made the whole situation much harder and this was very upsetting for us.

The participant P12 (a physician-General Practitioner) was of the opinion that neonatologists and parents should communicate more effectively and utilize a shared decision making approach to determine the care plan. However, she did not emphasized that the factors contributing to ineffective communication may include poor physician communication skills. She emphasized on the paternalistic attitude of the physicians rather than on their poor communication skills. She emphasized,

You know what is not really that great is that here in Greece we work more paternalistically... whatever we feel is right... we are the experts and we know better than anyone else what is good for the child and we just inform the parents or the guardians. We don't really co-decide with them. So in this context I feel that getting the communication right is a hard task to balance ... and this was a difficult aspect for me to comprehend. One thing to mention with my emotional hat on is that I was mentally drained as a result of this average or even probably bad communication that was established with the team. Now...

\section{Organizational and structural aspects of NICU environment}

Complexities of the highly technologized NICU context can cause parents to feel they cannot do what they believe to be the right thing during their infant's illness and therefore can predispose them to experience moral distress.

\section{Preventing mothers from caressing and touch across the body of their baby.}

Mothers know that emotional engagement, affective touch and caressing their infants is one of the most important means of speeding up their early development. While emphasizing that the skin-to-skin contact between baby and parent can be beneficial for both, participants in this study placed considerable emphasis on the benefits it offers to improve their infant's outcomes rather than on the benefits it offers to reduce their own feelings of psychological distress.

The participant P6 said, 
I just wanted to stroke her, use my fingertips across my neonate to offer her maternal love, affection \& warmth and these were things that surely would help the baby develop.

In the same vein, the participant P5 said,

I was only able to observe my baby for a couple of minutes and then had to go, although it is well known that contact with the mother is really helpful for the baby. Isn't that right? Well I was not able to give to my baby this so much needed contact.

Preventing the mother from having a skin-to-skin contact with her infant was an important reason why the participant P10 had a negative attitude towards performing reintubation on her infant, despite the physicians' dissenting opinion and the clear medical evidence to the contrary.

\section{Preventing mothers from providing milk for their babies}

Mothers know that providing their babies with their own breast milk is beneficial for their babies. However, while this is beneficial for both, participants in this study placed considerable emphasis on the benefits it offers to improve their infant's outcomes rather than on the benefits it offers to reduce their own feelings of psychological distress.

Two participants complained that while they were pumping their milk for their infants, the NICU staff repeatedly rejected it. As they regarded the rejection of their milk by the NICU staff as not only medically but also morally wrong, they felt intense moral discomfort which, however, did not spark a disagreement or conflict between mothers and NICU staff.

The participant $\mathrm{P} 10$ said,

I was told that my milk was not helping my baby.

In the same vein, the participant P14 emphasized,

How is it possible for formula to be better for my baby than my expressed breast milk? I thought that breast milk would help my baby more than formula.

The participant P17 observed decrease in her milk production because of emotional distress due to the traumatic experience of having her infant in the NICU. Then, she offered to send in the NICU milk produced from her friend who was breastfeeding. However, the NICU staff rejected it and her discomfort escalated into disagreement between her and the NICU staff. She said,

They didn't accept it and at that point I disagreed with them and I was upset again...

\section{Shortages of manpower and available medical devices necessary in NICU}


Lack of resilience for dealing with the imperfection of the health care system may lead to anger at the injustice of the circumstances and can play a crucial role as a reason behind parental moral distress. Health providers working in NICUs are working in a context of scarcity in (human or material) resources. This situation perceived by parents as morally stressful. The participant P12 who is a clinician (GP) emphasized her moral strain rose from the shortage of both human and material resources (such as an available infusion pump). She tended to attribute the reasons behind the bad communication between parents and physicians as well as the failure to engage in ethically optimal shared decision making to shortages of human resources and physicians practicing paternalistic mindset.

In the same vein, the participant P8 said,

We appreciated that the ICU was understaffed, as the medical team was constantly working really hard. And they had some pretty touch medical cases to deal with.

\section{The image of a long-suffering baby}

From the interview data analysis emerged that witnessing the baby's suffering may play a role as a reason behind parent moral distress. The image of a sick baby with tubes inserted in their body and especially in the mouth can be morally stressful to parents.

The participant P3 said,

At the end we agreed to him being re-intubated. There was nothing that could be done. There we were again with all these tubes down him and with the tube through his mouth.

In a similar vein the participant P11 emphasized,

They insisted that this was the right treatment for my child but the only thing I could see was tubes coming out from everywhere.

The same holds for the image of a baby suffering from uncomfortable sensations due to needles or catheters getting across to a blood vessel or being introduced elsewhere in their body.

The participant P9 said,

Yes I disagreed openly when I saw the midwives poking him to try and get a vein or every time they changed his catheter. I could not understand why they had to do this every 3 to 4 days.

\section{Internal factors of parents as resources of parent moral distress}

\section{Spiritual / existential factors}

From our data analysis emerged spiritual and/or existential factors which can serve as resources of parent moral distress. From our data analysis emerged spiritual or existential reasons behind why parent 
want "too much". The neonates of the participants P14 kaı P15 were described as having a little chance of recovery or extremely poor prognosis (in the case of P15) and were expected to live with severe neurological disorders and be medically dependent for their short lifetime, in the best circumstances. Neonatologists considered the continued provision of medical care or treatment to the babies to be futile and depriving other babies (having better prognosis) of the opportunity to be admitted in the NICU and receive lifesaving care or treatment. They expressed their moral judgments of the neonates' quality of life very clearly. The mothers however strongly opposed withdrawal of life-sustaining treatment and refused to give their consent. They refused to regard the care of their baby as futile. Parents requested ongoing life-sustaining treatment whereas the neonatologists recommended redirection of the care to comfort care for the infant. Importantly, parents in denial about what neonatologists labelled as medical futility had interesting reasons to refuse to admit the truth or reality of such an unpleasant medical decision. The participants' concerns were revolving around their own personal core values and beliefs.

The participant P14 was intensely annoyed and deeply irritated by the fact that the neonatologists adopted very cynical attitude while communicating their moral judgments to her. In the participants' words,

If it was God's will for him to have some sort of disability or any other complication, I was ready to face this with the support of my partner. But this lack of empathy \& arrogance that came across every time they informed me of my child's situation completely enraged me and stressed me out...they just carried on with their jobs as normal without giving a damn that they were talking about a human being.

While the participant P15 tried to justify the neonatologists' moral judgments, she has strongly defended her need to show a lot of love and affection to her baby until the baby's last breath. Moreover, she defended her need to seize what God or Nature sent to her by engaging her in such an adventure. It is noteworthy the following long quote from her interview:

They gave me the impression that they wanted to get done with this baby and that it was a burden to the unit. Ok I can appreciate this ... Every day they kept telling me that we are putting the baby through unnecessary pain and that I don't consent to make this stop, that he is just mechanically supported and even if he was to recover, I would take him back home with many complications, creating a burden to me and my family. But I didn't feel that way. This was a live human being, and if it was meant to be that way then this baby came to our lives to teach us a lot of things, even if it meant that we would lose him early. He was borne with a heart that was beeping and life within him. I could not let him go and take such a decision. And to be honest I have not regretted that decision. Me and my husband both agree that despite what we have been through we have no regrets for taking that decision as it made us have more empathy and appreciation towards families with disable children. Unfortunately, after just one month we lost him. We knew it was coming ... but at least I had the opportunity to offer him what I could. A home, a mum, a hug from dad. We were at home preparing ourselves about what was to happen \& that we had to say goodbye but at least we would do this in a way that we felt itwas right and in our own environment. 
Please, note that while the participant P5 held opposing attitude toward removing life-sustaining treatment from her baby, her objection was oscillating. Her decision to take home a baby with severe neurological disorders was not absolutely unwavering. She said,

I won't forget one day, I was in the unit \& the neontologist told me that my child will make it however she was not aware of what disabilities he may end up having once at home. Maybe I said to myself maybe should I wish that the baby did not survive? You see I got to the point to consider this... having a child that could not see, hear, one that would be both physically and mentally disabled, unable to move.

\section{Parents' self-directed negative emotions}

The participant P7 placed considerable emphasis on her negative self-directed emotion (guilt).

I felt guilty as I thought this could be my mistake. I was not very careful and gave birth prematurely. Afterall my immediate family environment had a lot to do with placing that guilt on me..even my husband was not very supportive. I asked one of the neognologists who was working that shift how do I know that they have given me the full, true picture.

After removal of endotracheal tube, the infant of the participant P17 did not gain weight. The baby was not tolerating enteral feeding even when food was carrying through a nasogastric tube. The participant P17 also reported feeling guilt and complained,

Due to being so upset, my milk supply reduced and I could not breastfeed his twin sister. I felt so guilty but thankfully my mother and partner were very supportive.

\section{Factors related to parent decision-making process}

\section{a) Dealing with treatment success rates}

From our interview data analysis emerged that disclosing to parents with an infant in the NICU specific information about the treatment success rates, this may serve as a resource of parent moral distress. Participants reported that parents are not interested in statistics but just serving the best interest of their infant, on the understanding that every single case is a different case.

The interview quote of the participant P9 presented below is representative. She said, When it comes to your child percentages are irrelevant ... what matters is just for your child to get well and nothing else.

\section{b) Assuming perceived unbearable responsibility for the baby}

Participants would prefer to feel that the physicians who are responsible for the care of their infants were much more sure of what they were believing to be the right course of action for curing the infants' illness. 
Participants would rather leave the responsibility of making a healthcare decision for their infant in the hands of the attending physicians and allow them have control, authority and responsibility over their infant's healthcare.

Parents do not bear the weight of responsibility in making difficult decisions. From our data analysis it was emerged that while parents with infants in the NICU claim for their greater involvement in decision making, participants being faced with difficult dilemmas had better to avoid taking full responsibility.

The interview quotes of the participant P3 and P9 presented below are representative.

The participant P9 said,

I was really upset that I had to make that choice for my child

In the same vein the participant $\mathrm{P} 3$ said,

Then I had a go at the doctors who kept asking over and over again, probably because they wanted to avoid taking full responsibility for the outcome.

\section{c) Parents' reservations and fears of making a particular decision}

The participant P4 came across a dilemma perceived as extremely difficult because of her unwillingness to come to terms with truth. She described the fear of knowing the truth (truth phobia) by doing a karyotype genetic test and said,

I have been deeply traumatized as a result... I will never be able to get over this .

\section{Moral schisma: a conceptually distinct concept}

Parents may find themselves in inescapable situations which demand moral decisions despite the fact that every possible option is equally likely to result in adverse effects to the ill infant. It is true that there are really inextricable dilemmas in situations where the expected good and bad outcomes are equally likely.

\section{Being faced with inextricable (according to objective evidence) dilemmas}

\section{a) Medically inextricable dilemmas}

Participants were faced with an extremely hard-to-solve dilemma regarded as inextricable even from a medical evidence-based perspective. As the available evidence was completely i inconclusive, the parents were at a loss of what would be better choice to serve the infant's best interest in the particular situation. The goal of making a deliberate and well-balanced decision was perceived to be unattainable. 
In the case of the participant P9 the parents had to come across such a moral dilemma. They had to choice between opting to continue along the path of the tried and tested treatment already provided and opting for a recommended medical novelty which however involved greater risks. The medical novelty was expected to further improve the patient outcomes (infant's lung function). While the decision making was a practically inescapable process, it was extremely difficult (almost impossible) for the parents to decide which of the two options was the better for their baby. The participant P9 said,

To apply a therapy protocol which carried a high risk of complications? They could not make such decision and eventually they said "please do whatever is best for our baby. During that time I was under a lot of stress and was feeling pretty run down so I looked at them to decide what to do based on their experience.. what would you do if this was your child? But they would not answer that question. Each doctor had a very different opinion on the matter and even after consulting with other doctors they also responded that each case can be different".. "the more I asked the more I confused myself".

\section{b) Dilemmas that parents arguably perceive to be inextricable}

Physicians and parents view the same dilemma from different perspectives. Physicians' decisions are based on their knowledge and experience while parents decide and act on their emotions and instinct. As parents want to do what is best for their infants, even a little success or failure rate counts a lot to them. While there was no escaping the need to make decision on an objectively hard-to-solve dilemma which, however, parents (not physicians) perceived to be inextricable, participants stopped deliberating and just said an OK. Note, however, that, this was not a genuine decision. In this perspective, they made their decision based on a mechanical (formal, statistical) consideration of relevant data parameters and variables. Their decision was based on what they perceived that would be the average person's decision in the exact same circumstances. They chose the option that seemed more likely to increase the shortterm rather than the long-term risk aversion. The patients' internal tug of war remained, however.

In the case of the participant P13 there was agreement between physicians about the severity of the infant's condition ("hopeless" patient with very poor prognosis). In the words of the participant,

One supervisor said: "Right guys, we need to try really hard here and whatever is to happen will happen... after all, the child's prognosis is not that good so I don't expect that he will make it ... so lets stop making it harder for him for no reason". There was another one who agreed and said: "Guys there is no hope here, let us do what we can do here and let's say we have tried and we should be ok".

However, they left open the possibility that the infant might be successfully treated if an expensive critical care transportation to a specialized medical facility would be carried out. It was a highly morally stressful situation, arguably perceived as inextricable situation in the particular circumstances. She emphasized,

What a turmoil we went through...panic is probably the best description of how we felt along with despair. So who can tell us what is best for our child? They didn't know either ... I cant judge them to be honest ... it is possible that they had not come across this situation before. After shedding a lot of tears and thinking 
it through with my husband we decided to transfer the child under our responsibility to the closest specialist center.

Furthermore, the participant $\mathrm{P} 3$, was coming across a dilemma which however she perceived to be "inextricable" despite the fact that all the physicians insisted on performing intubation on the ground that the situation left them no option but to perform it. She emphasized,

To allow them to re-intubate him bearing in mind all the risks involved or not? But if he ended up dying during an apnea episode...pure madness... madness... what is ultimately the right thing for the baby? You are not in a position to know really.

Furthermore, it is noteworthy that the participant P3 commented her secondary experience of very difficult dilemmas between two equally risky (and beneficial) choices for other infants in the NICU. She described and commented in a best way the experience of a parent who was caught in and had to cope with a truly intractable situation. She put it best in saying,

What do you do in this situation? I don't know..i don't really know how these people take such a decision? Do they rely on their instinct, do they pray or do they meditate? I really don't know...overly complicated situation. I wish no one finds themselves in that situation... these poor parents were discussing the options with the doctors over and over again.

\section{c) Dilemmas perceived to be inextricable because of internal factors of parents}

The participant P4 perceived a dilemma (presented above) as inextricable because of her own perceptions and internal constrains.

The participant oscillated between letting herself know the truth and turning her ears away from the truth because of her fears, which, in our opinion were reasonable under the particular circumstances. The infant was not expected to be benefited substantially from the result of the karyotype genetic test, which however, might be extremely stressful for the parent.

\section{The important role of family pediatricians or a friend who is a physician}

In the case of two participants in our study, their concerns about whether the most appropriate treatment for their infant had been selected (by the NICU physicians) was profoundly shaped by the opinion of the family pediatrician. Parents need to feel they can trust their pediatrician. Parents who have to deal with a dilemma regarding their infant's treatment ask their family pediatricians (or other physicians who are acquainted with them) for medical advice.

The participant P3 said,

My view was that we should really try using some sort of medication and oxygen so that the child didn't have to be re-intubated. I was in constant communication with my pediatrician over the phone who said 
that they should try a bit more before proceeding with re-intubation but he was not able to see the state of my baby. The neontologists there kept saying :"what are you talking about madam, this is not possible, your baby is in danger".

In the same vein, the participant P2 emphasized,

On our way to the hospital, in the ambulance I was talking to the pediatrician who told me that intubation can lead to complications and therefore they don't proceed unless it is absolutely necessary. And you know there are so many times in my life it's like time goes back to that moment and think that maybe he was right, as the child is now 2 and has hoarse voice.

\section{The parent's immediate environment}

\section{The role of relatives' or friends' previous experiences}

Parents' concerns about whether the most appropriate treatment for their infant was selected can be profoundly shaped by their own personal previous experiences or the previous experiences of a close family member, or even a friendly person.

The participant P2 said,

How am I expected to know whether the blood used in the transfusion has been checked or not, I asked him? What are you talking about madam, he responded. I just had a bad experience I said as my mum was infected with hepatitis $b$ following a blood transfusion after an operation.

Furthermore, the participant P11 said,

To be honest I didn't want the baby to be intubated at all. It was not that I had a particular concern, just I had heard from a relative that their baby didn't make it.

\section{The attitude and role of the husband (neonate's father)}

Participants reported that during the infant's hospitalization the role of the partner was to calm her down, being cool-headed and clear headed but also supportive. In the dilemmas raised by the mothers and whilst the doctors provided no choice solutions, fathers remained calm and they were also seen to calm down the distressed mothers and to convince them to follow the doctor' s advice. When faced with difficult dilemmas, husbands lived through the agony of their wives with the later always having the leading role. Fathers tended to react more rationally rather than emotionally in contrast to the mothers. The following quotations illustrate the findings.

The participant P2 reported that her husband told her,

Please...stop being stupid, the child is in their hands...

In a similar vein, the participant P1 said, 
...my husband was trying to calm me down...

Note that in morally extremely questionable situations that leave uncertainty inextricable, the husbands experienced distress and anguish together with their wives.

The participant P13 said,

The responsibility and the accountability for that decision was on me and Kostis [my husband] ... and yes to be honest following hours of thinking it through \& crying my eyes out we decided with Kostis to take her to another unit.

In the same vein, the participant P3 said,

I don't know .. what we have experienced felt like a very hard puzzle that myself and my husband had to get to the bottom of.

In a similar vein, the participant P10 said,

......Both me and my husband were totally disappointed.

\section{The role of family and friends}

The role of family and friends may be supportive or even predisposing factor to parent moral distress

The participant P8 said,

Thankfully, I received a lot of mental and emotional support at that point from my partner and my best friend.

Note, however, that the participant P7 said,

I was feeling guilty, thinking that I might have caused this by mistake. I didn't take care and went into labor prematurely. My immediate family environment made me feel even more guilty about my actions around this ... even my husband was not very supportive.

\section{Mild moral residue}

Parents' tepid emotional reactions to morally distressing past events were emerged from our data analysis. Most participants felt a partly positive and partly negative reaction to the past event of their infant's hospitalization in the NICU. Participants felt that their concerns about the rightness or wrongness of a decision with regard to the act that was taken during their infant's hospitalization were lingering in their mind for a long time after the infant had been discharged from the NICU. Parents who came across moral distress during the period of their infant's hospitalization may feel lingering mental

The participant P12 said, 
At the back of my mind, I keep thinking that maybe we would not have these problems if there was an immediate treatment plan drawn for necrotic enterocolitis and we had started an appropriate nutrition plan such as enteric friendly diet.

In the same vein, the participant P10 emphasized,

If you ask for my view, I believe we could have avoided all these issues if we have been treated differently.

In a similar vein, the participant P13 complained,

Seriously I am not trying to put the blame onto the NICU staff, but I think valuable time was lost when they mistakenly diagnosed the heart tumor in the first place. That's it from me.

The infant of the participant P8 had been reintubated despite the strong concerns she had. Then, the infant survived sepsis and finally got better and was discharged home. The participant said,

Now every time the child has high temperature I am worried it might be sepsis. This word has been stuck in my mind. I will never forget what we have been through.

Note, moreover, that our analysis revealed that participants demonstrated much more humility about health care providers' abilities. Note, moreover, that while participants at the time of interview had still vivid memories of the event of infant's hospitalization in the NICU as well as their reactions, their lingering moral distress was mild.

Last, it is noteworthy that all the participants who had concerns as to whether the appropriate treatment or medical intervention was recommended or performed during the infant's hospitalization, in hindsight they would have approved these interventions despite the continuing existence of mild residual concerns at the back of their minds.

\section{Discussion}

Below, we provide a discussion on some points that raised in the Results section of this study.

\section{Defective communication between physicians and parents or defective shared decision making as reasons behind parent moral distress}

As reported in literature, "ineffective or insensitive communication [with healthcare providers] and insults to the parent - child relationship that conjure feelings of mistrust" are driving forces behind parent moral distress or even moral residue (Mooney-Doyle and Ulrich, 2020) [9]. It is argued that parents want honest and compassionate communication and information, and value the support and respect for their parental role. Mooney-Doyle and Ulrich state: "Another aspect of cultural misunderstanding that caused distress for parents was healthcare providers' perceptions of who should be involved in decision making" (Mooney-Doyle and Ulrich, 2020) [9]. As good communication never "happens", training health care 
providers in communication skills could make health care providers-parents communication more effective and mitigate parent moral distress in the NICU environment.

\section{Difficulty in determining infant's best interest as a contributing factor to parent moral distress}

During the interviews participants wondered who knows what the infant's best interest is. This is a recurring theme throughout the narratives. Given the great degree of uncertainty in the context of neonatal intensive care, it is challenging to determine if the treatment being provided to a neonate has a likelihood of success and ultimately what defines success or failure for a particular neonate (Mills and Cortezzo, 2020) [13]. In that regard, parents have feelings of uncertainty and medical concerns (Sneath, 2009) [30].

Parents feeling unable to carry out their parental role as a reason behind parent moral distress

Infants' hospitalization in the NICU may challenge the parents' sense of ability to carry out their parental role and cope with their responsibilities (Raines, 2013 [31]; Verberne et al., 2017 [32]; Loewenstein, 2018 [7]). Parental involvement in determining their infant's health care plan can strengthen their sense of coherence and ability to achieve their parental role at the NICU environment (Aarthun, Øymar and Akerjordet, 2019) [33].

\section{Negative self-directed emotions as facilitators of parent moral distress}

Campbell, Ulrich and Grady put it best in saying that moral distress (broadly understood) encompasses negative self-directed emotions. (conceptually distinct from other negative moral emotions, such as selfcriticism, guilt, shame, anger, embarrassment, and diminished self-esteem) or attitudes, which arise in response to one's perceived involvement in a morally questionable or undesirable situation (Campbell, Ulrich and Grady, 2006) [22].

\section{NICU environment - related parent moral distress}

A category of variables related to parent moral distress are related to the NICU environment. It is to be noted that the frequency of maternal NICU visitation is inversely related to maternal depression and longterm maternal distress (Greene et al., 2015 [34]; Harris et al. 2018 [35]). Preventing mothers from providing their milk for their infants in the NICU or preventing mothers visitation and participation in skinto-skin care are stressors inherent in a typical NICU environment (Gonya and Nelin, 2013 [36]; Greene et al., 2015 [34]). In this study, the data analysis revealed that such stressors may facilitate not only parent psychological distress but also parent moral distress. The same holds for the image of a neonate being in the NICU, perceived as long suffering (i.e. intubation, often performed venipunctures).

Preventing mothers from providing their milk for their hospitalized infant can act as a stressor for mothers (Rossman et al., 2013) [6]. As it was emerged from our study, it can cause them to experience not 
only moral distress but also other types of psychological distress. Mothers with an infant in the NICU have faith in their milk and choose to provide it to the infant as their only contribution to optimize their infant's outcome. As mothers of infants hospitalized in the NICU want to do what is best for their infants, they prioritize the infant's needs over their own and despite multiple barriers they strive for achieving their self-stated goal to provide human milk to meet the nutritional needs of their infant (Rossman et al., 2017 [37]). Providing their milk to their infant causes mothers to feel a connection with the infant and relieve their negative emotions (i.e. failure and guilt) related to delivering a premature infant (Rossman et al., 2013) [6].

Parents close physical proximity to their neonates has been very recently highlighted in the literature. It is argued that parents' unrestricted close physical proximity to their neonates ( 24 hours per day in singlefamily rooms) offers to them active participation in the care provided for their infant and helps them to gain insights into the neonate's condition. Moreover, it helps them "to achieve independent parenthood at the time of discharge" and make them feel respected and gain "self-management tools" (Stelwagen et al., 2021 [38]). As reported in previous literature, NICUs have been redesigned to facilitate parents' skin-to-skin contact with their infants by facilitating their all-day presence in the NICU ("rooming-in") (Serpero et al., 2013 [39]; Lester et al., 2014 [40]). The so-called "rooming-in" has both positive and negative effects on parents (Garfield, Lee and Kim, 2014 [41]; Aagaard et al., 2015 [42]).

Preventing mothers from providing their own milk for their infants or having a skin-to-skin contact with them may spark disagreement or conflict between mothers and health providers in the NICU context. The discrepancy between parents' and health providers' expectations of their roles may challenge the interchange of roles and responsibilities between them (Aagaard et al., 2015 [42]).

Last, note that Staver et al. had previously concluded that NICU environment is one of the variables associated with parent moral distress in the context of neonatal intensive care (Staver et al., 2021) [43].

\section{Medical futility}

While having an infant in the NICU is often psychologically traumatic and generate some moral distress (Janvier et al., 2016 [3]; Prentice et al., 2021 [4]), it is argued that perceived disagreements between healthcare providers and family members in the NICUs are very rare (Prentice et al., 2021 [4]). In the vast majority of cases in which there is disagreement, parents are said to "want too much". That is to say that parents want ongoing intensive care whereas the clinicians recommend comfort or palliative care for the infant (Prentice et al., 2021 [4]). Because of the extreme uncertainty in neonatal intensive care that is an extremely unpredictable process, NICU infants may be saved while being medically dependent for a lifetime. These infants are harmed unwittingly. This is called "benevolent injustice" (Barnum, 2009) [44]. Parents' demands for continued aggressive care may be a facilitator of professional and parent moral distress. Note that Hamric and Epstein found that family members requesting aggressive treatments may be among the most significant reasons behind parent moral distress in NICU health care professionals (Hamric and Epstein, 2017) [45]. Then, the health care professionals' moral distress may cause parents to experience moral distress (broadly understood) because of the dynamic interaction between parents and 
health care professionals. It is arguably stated that physicians' "maladaptive responses to moral distress may result in "transference" of moral distress" on to the families of babies for whom physicians have a duty of care (Prentice et al., 2018) [46].

Note that in neonatology the role of the so-called "zone of parental discretion" (where parents' decisions may conflict with the decisions a clinician) and "grey zone" (where parents can choose between resuscitation or palliative care options) is highlighted (Wilkinson, 2016) [47]. Parents "wanting too much" are often the reason for providing disproportionate care (Prentice et al., 2021 [4]). In the limits of the socalled Zone of Parental Discretion parents may request non-recommended treatment (Gillam, 2015) [48]. In the study of Prentice et al. (2021) it is stated: "An ethics framework is necessary to assist clinicians in assessing whether the provision of lifesustaining interventions falls within the zone of parental discretion, irrespective of their own personal views" (Prentice et al., 2021 [4]). At any rate, it should be highlighted that futility necessarily has subjective aspects except in the case of brain death. The qualitive and quantitative dimensions of futility often rely on value judgments and more particularly on judgments on the quality of life, which however, often go beyond the physician's professional activity (Swetz et al., 2014) [18]. Furthermore, parents may ask for ongoing intensive care because the recommended redirection or withdrawal of the treatment provided compromises their moral integrity or goes against their own core values and beliefs that are stable over time. This is the case with participants in our study who declared their negative moral emotions that arose in response to their perceived involvement in a highly undesirable moral situation. Mooney-Doyle and Ulrich who have recently offered an integrated account of parent moral distress put it best in saying: "Moral distress involves the perception one failed, due to internal and external constraints, to behave in the morally right way or compromised one's own moral integrity or values" (Mooney-Doyle and Ulrich, 2020) [9]. Participants in our study felt compromised their core values and beliefs associated with spirituality and their love for human-beings and respect for their existence in the world. The NICU health care providers should worry about and make an effort to understand the reasons behind why the parents are expressing a strong desire for ongoing treatment. NICU health care providers should be supported to develop their skill of empathetic thinking ahead to achieve this task.

Last, while the intrapersonal dimension of the updated account of parent moral distress offered by Mooney-Doyle and Ulrich encompasses parents' expressed angst over their role of being a parent to multiple children, in our study none of the participants expressed such angst, despite the fact that many participants had more than one child [9].

\section{Moral schisma}

Foe et al. put it best in saying moral schisma is a "significant internal struggle with personal values" because of a genuine uncertainty regarding the newborn's care, that involves "covered signs of distress" (Foe et al., 2018) [21]. However, in this study we offer a slightly different notion of "moral schisma". We regard the Foe's et al. definition of moral schisma as being encompassed by the broad definition of moral schisma, which might be viewed as "ethical confrontations" (Janvier et al., 2007) [49]. There is "moral schisma" if and only if the moral dilemma splits the parent's inner world into two divisions. This may 
happen when a parent is faced with a hard-to-solve moral dilemma between two mutually exclusive options, in the medically (and morally) uncertain context of neonatology. While according to the Jameton's original (strict) definition of moral distress the parent has made a clear judgement about what course of action should be taken but is prevented from acting accordingly, in the broad sense of the term moral distress the parent experiences anguish because of medical uncertainties. Notwithstanding, in case of moral schisma the parents cannot make a clear judgment at all. This moral dilemma cause parents to experience feeling of suffering from anguish which, however, is not expected to be alleviated in the light of the actual circumstances. Facing (many and serious) moral dilemmas in extremely uncertain circumstances and in the inherently stressful environment of NICU is likely to cause parents to experience moral schisma.

In the broadly defined moral distress, the parents feel that their actions or decisions conflict with their core values and deeply held beliefs, resulting in them experiencing a state of mental discomfort, anguish or anxiety. While it is arguably suggested that one of the competing options for treating infant's medical problem(s) overweighs all others and therefore should be selected, the parent is not entirely convinced and raises concerns about whether the right and morally sound course of action has finally been taken. These concerns prevent the parent from wholeheartedly accepting the treatment being provided and cause them to worry so much about the suitability of the treatment and experience distress. Notwithstanding, according to the here offered concept of moral schisma, in moral schisma the parent cannot make a clear moral judgment about what course of action should be taken due to the fact that while there are competing options no single option can be arguably regarded as an option that clearly overweighs any another in that situation. While moral distress is strictly related to moral uncertainty and sense of responsibility, moral schisma is conceptualized in a more internal manner. It is conceptualized as an internal conflict which has been escalated into a full-blown conflict, and which, hwever, is fruitless, namely, is unable to reach a resolution.

Parent moral schisma may be produced from internal conflict that may emerge from parents' core values discrepancy. Discrepancy in the core values can lead to a fruitless struggle within a parent's mind over a decision or moral question regarding the infant's treatment. For instance, there may be a fruitless conflict between parents' autonomy (their need for having their decisions respected by the clinicians) and their humility about the powers of science. Such a situation arises from the parents' involvement in a situation they perceive not only as morally questionable but also as inextricable. We regard parents' moral schisma and moral distress in the NICU as conceptually distinct albeit strictly related or overlapping concepts.

More precisely the findings in this study allow for a sharp line of conceptual distinction to be drawn between parent moral schisma and moral distress in the neonatal intensive care unit environment. In line with the findings of this study, we propose a combined subjective-objective approach to make a conceptual distinction between parent moral distress and parent moral schisma. Parent moral distress occurs when coming across a moral dilemma where parents raise strong concerns while a solution appears reliable. Parent moral schisma occurs when the parents are left no choice but to come across a moral dilemma which is or is perceived as inextricable. 
In line with our approach, there is parent moral schisma when the following conditions are met: a) The parents are at a loss of what to decide to serve the best interest of their infant in the particular situation.

b) They experience intense internal conflict. c) They are faced with dilemmas which are inextricable or perceived as inextricable. d) The dilemma's inextricability or perceived inextricability are based on the available objective medical evidence. This approach is practically necessary to develop successful strategic plans to mitigate or eliminate parent's anguish or emotional strain related to moral dilemmas.

\section{Mild moral residue}

Bringing infants home after having stayed in the NICU, parents may experience this transition period as a period of mixed feelings (i.e. happiness and anxiety) (Raines, 2013) [31]. The participants in our study a long time after the infant's hospitalization experienced mixed feelings (happiness and mild lingering concerns). Lingering moral concerns or distress are reported in the literature as moral residue. "Moral residue refers to the lingering feelings that remain once the morally distressing situation has passed" (Prentice et al., 2016) [26]. Moral residue was a recurrent finding throughout the participants' narratives. If moral residue can cause damage over time remains to be explored. Note, however, that the traumatic event of heaving an infant in the NICU may have some positive effects. It is argued that parents who had previously experienced such an event feel like having built resilience for dealing with life challenges Importantly, they feel stronger that they think (Janvier et al., 2016 [3]).

\section{Relational account of parent moral distress}

In recent years, the literature created a perfect breeding ground for a conceptualization of the complex phenomenon "parent moral distress" as a relational notion. It is noteworthy that the relational dimension of health professional moral distress in the NICU environment had already been highlighted in the literature. Prentice et al. conducted a literature review and stated that moral distress literature has placed emphasis on ethical climate rather than on mental aspects of moral distress (Prentice et al., 2016) [26]. During last years the relational account gains ground in the literature not only with regard to parent moral distress but also with regard to parent psychological distress. Loewenstein (2018) in her literature review study on parent psychological distress highlight the interpersonal factors, including "the relationship between the parents, the parents' relationships with other friends and family, and the social support the parents accept and receive" [7]. According to the Walsh's (2018) definition of parent moral distress parents may experience moral distress when perceive themselves as unable to meet their caregiver obligations. This "care ethical" account of moral distress highlights the relationship between the caregiver and their cared. Two years later, Mooney-Doyle and Ulrich provided an integrated threedimensional account of parent moral distress that emerged from their literature review: "an intrapersonal dimension, an interpersonal dimension, and a spiritual/existential dimension" [9]. In intrapersonal moral distress the fulfilment of parental roles, duties, or obligations are perceived to be threatened. Furthermore, the intrapersonal dimension may be related to parents' "everyday life and managing employment needs, finances, and concerns for other family members" [9]. Therefore, parents may feel overwhelmed and experience feelings of self-directed negative emotions. Importantly, none of the participants in this study emphasized the impact of their moral distress on these needs or concerns. Furthermore, Mooney-Doyle 
and Ulrich state that the intrapersonal dimension "...includes consideration of treatment options and decisions regarding their child's healthcare...In doing this, parents reflect on the child's quality of life with the child's provider(s) or quietly to themselves" [9]. Participants in our study highlighted this aspect of the intrapersonal dimension of parent moral distress.

In conclusion, the findings that revealed from our data analysis confirm the relational account of parental moral distress offered by Mooney-Doyle and Ulrich. Note, however, that the findings emerged from our data analysis highlight the interpersonal and the spiritual/existential dimension of the account parental moral distress rather than the intrapersonal dimension of the aforementioned integrated relational account.

\section{Limitations}

Most participants in this study expressed agitation induced by recalling memories about their infants' hospitalization in the NICU. The interview outcomes might be somehow affected by participants' agitation. Note, however, that we observed many descriptive details in interviews, which were supported by non-verbal communication types, leading us to consider that the time gap between infant's hospitalization and interviews did not significantly affect participants' ability to accurately recall past exposures (recall bias) and convey their own personal lived experiences to the interviewer. Many participants (particularly P3 and P13) were emotionally charged at the time of the interview, experiencing strong emotions that were probably difficult to control. Therefore, emotional bias cannot be excluded. Furthermore, in this study we did not explore the wider understanding of parental moral distress in the context of family life. Parents may experience moral distress not only as a direct effect (i.e. of making decisions for their infant in the NICU), but also indirectly because of the impact (of the stressful event of having an infant in the NICU) on other family members for whom they perceive they cannot meet their caregiving obligations (caregiver moral distress) (Walsh, 2018).

Moreover, one should bear in mind that the infants of the participants in this study were alive at the time of interviews. Parents of infants who died in the NICU or at a later time were excluded. Last, self-report bias cannot be excluded because the participants knew the interviewer was a pediatrician.

\section{Conclusions}

The most relevant categories of variables associated with parent moral distress were a) physician-related (various factors), b) parent-related, c) parent's context (family or broader social)-related, and d) NICU environment-related. While many findings of the present study are in line with previous studies, our data analysis revealed findings which - to our knowledge- are little recognized in the available literature. Three categories of parent moral distress resources have been identified: Parent concerns about the whole care plan or a single medical intervention, medical futility and physician inability to make clear decisions. While parents with infants in the NICU initially needed for having their decisions respected by physicians, they ultimately shew a tolerant attitude towards benevolent medical paternalism. However, many 
physician-related factors may serve as facilitators of parent moral distress. The important role of the family pediatrician in creating parent moral distress is highlighted. The same holds for factors related to family or wider social environment. Furthermore, the role of parent's internal factors (especially spiritual/existential core values or beliefs) as well as the role of NICU environment-related factors (such as the image of a long-suffering infant, preventing mothers from providing their own milk for their infants and having a skin-to-skin contact with them) in creating parent moral distress are highlighted. No more than mild moral residue was found among parents with infants previously hospitalized in the NICU. Moreover, we offer an updated account of parent moral schisma as a conceptually distinct from moral distress phenomenon. Parent moral distress and moral schisma in the neonatal intensive care context are conceived as conceptually distinct albeit strictly related or overlapping phenomena. Empirical research using this distinction might contribute to further operationalize the concept of moral schisma in the neonatal intensive care context. Last, the findings that revealed from our data analysis confirm the relational account of parental moral distress offered by Mooney-Doyle and Ulrich. The findings of this study might contribute to parents being helped to demonstrate resilience and further decrease their NICUrelated moral distress.

\section{Abbreviations}

NICU = Neonatal Intensive Care Unit

$\mathrm{CT}=$ Computed Tomography

\section{Declarations}

\section{Availability of data and materials}

The transcripts of the full interviews that were collected and qualitatively analysed in the current study are not available due to the ease with which study participants could be identified. The redacted transcripts used and analysed during the current study can be made available by the corresponding author on reasonable request.

\section{Acknowledgements}

We would like to wholeheartedly thank all the mothers who offered their insightful input as participants in this investigation.

\section{Funding}

The authors thank the Aristotle University Research Dissemination Center (KEDEA) [Number 99069] for their contribution to the financing of this publication. The funding sources had no role in the study design, data collection, analysis, and interpretation, or writing and preparation of the manuscript, or decision to 
publish. The content of this manuscript is solely the responsibility of the authors and does not necessarily represent the official views of funders.

\section{Author information}

\section{Affiliations}

Laboratory of Forensic Medicine \& Toxicology (Medical law and Ethics), School of Medicine, Faculty of Health Sciences, Aristotle University of Thessaloniki, University Campus, GR 54124, Thessaloniki, Greece.

\section{Authors' Contributions}

PV was responsible for the study conception, data analyses, ethical analysis of the findings, writing of the paper and reporting of the study. MD interacted with the participants and performed the interviews, transcriptions, translations and initial analysis. ET assisted in the data analysis and revisions of the paper. All authors have read and approved the final manuscript.

\section{Authors' information}

Polychronis Voultsos is an Associate Professor of Medical Ethics. Maria Deligianni is a Pediatrician, Msc in Christian Bioethics. Eftychia. Tsamadou is a Child and Adolescent Psychiatrist, Msc in Medical Law and Ethics.

\section{Corresponding author}

Correspondence to Polychronis Voultsos

\section{Ethics declarations}

\section{Ethics approval and consent to participate}

Prior to participating in this study, the participants were given adequate information on the aim, procedure, nature and confidentiality of the study, processing of data according to the human study participant's research ethics approval. Subsequently, participants were asked for informed consent. The authors confirm that informed written consent was obtained from all subjects and/or their legal guardian(s). Only subjects who obtained informed consent voluntarily were included in the study. The study and consent procedure were approved by the Ethics Committee affiliated with Aristotle University of Thessaloniki, Faculty of Health Sciences, School of Medicine (Decision Number: 2.437/24-11-20). In addition, we confirmed that all methods were performed in accordance with the relevant guidelines and regulations. The authors confirm that all methods were carried out in accordance with relevant guidelines and regulations. The authors assert that all procedures contributing to this work comply with the ethical standards of the relevant national and institutional committees on human experimentation and with the Helsinki Declaration of 1975, as revised in 2008. 


\section{Consent for publication}

In this manuscript, personal details of participants are presented that compromise anonymity (Table 1). Written informed consent to publish this information was obtained from study participants.

\section{Competing interests}

The authors declare that they do not have any conflicts of interest to disclose.

\section{References}

1. Chertok IRA, McCrone S, Parker D, Leslie N. Review of interventions to reduce stress among mothers of infants in the NICU. Adv Neonatal Care. 2014;14(1): 30-7.

2. Segre LS, McCabe JE, Chuffo-Siewert R, O'Hara MW. Depression and Anxiety Symptoms in Mothers of Newborns Hospitalized on the Neonatal Intensive Care Unit. Nurs Res. 2014;63(5): 320-32.

3. Janvier A, Lantos J, Aschner J, Barrington K, Batton B, Batton D, et al. Stronger and More Vulnerable: A Balanced View of the Impacts of the NICU Experience on Parents. Pediatrics. 2016 Sep;138(3):e20160655. doi: 10.1542/peds.2016-0655. Epub 2016 Aug 3. PMID: 27489297.

4. Prentice TM, Janvier A, Gillam L, Donath S, Davis PG. Moral Distress in Neonatology. Pediatrics. 2021 Aug;148(2):e2020031864. doi: 10.1542/peds.2020-031864. Epub 2021 Jul 20. PMID: 34285081 .

5. Roque ATF, Lasiuk GC, Radünz V, Hegadoren K. Scoping Review of the Mental Health of Parents of Infants in the NICU. J Obstet Gynecol Neonatal Nurs. 2017 Jul-Aug;46(4):576-587. doi: 10.1016/j.jogn.2017.02.005. Epub 2017 May 12. PMID: 28506679.

6. Rossman B, Kratovil AL, Greene MM, Engstrom JL, Meier PP. "I have faith in my milk": the meaning of milk for mothers of very low birth weight infants hospitalized in the neonatal intensive care unit. $J$ Hum Lact. 2013 Aug;29(3):359-65. doi: 10.1177/0890334413484552. Epub 2013 Apr 18. PMID: 23599267.

7. Loewenstein K. Parent Psychological Distress in the Neonatal Intensive Care Unit Within the Context of the Social Ecological Model: A Scoping Review. J Am Psychiatr Nurses Assoc. 2018 Nov/Dec;24(6):495-509. doi:10.1177/1078390318765205. Epub 2018 Mar 26. PMID: 29577790.

8. Staver MA, Moore TA, Hanna KM. Maternal Distress in the Neonatal Intensive Care Unit: A Concept Analysis. Adv Neonatal Care. 2019 Oct;19(5):394-401. doi: 10.1097/ANC.0000000000000642. PMID: 31306234.

9. Mooney-Doyle K, Ulrich CM. Parent moral distress in serious pediatric illness: A dimensional analysis. Nurs Ethics. 2020 May;27(3):821-837. doi: 10.1177/0969733019878838. Epub 2020 Mar 5. PMID: 32138577.

10. Lasiuk GC, Comeau T, Newburn-Cook C. Unexpected: an interpretive description of parental traumas' associated with preterm birth. BMC Pregnancy Childbirth. 2013;13 Suppl 1(Suppl 1):S13. doi: 10.1186/1471-2393-13-S1-S13. Epub 2013 Jan 31. PMID: 23445715; PMCID: PMC3561145. 
11. Hagen IH, Iversen VC, Svindseth MF. Differences and similarities between mothers and fathers of premature children: a qualitative study of parents' coping experiences in a neonatal intensive care unit. BMC Pediatr. 2016 Jul 15;16:92. doi: 10.1186/s12887-016-0631-9. PMID: 27422718; PMCID: PMC4946152.

12. Spinelli M, Frigerio A, Montali L, Fasolo M, Spada MS, Mangili G. 'I still have difficulties feeling like a mother': The transition to motherhood of preterm infants mothers. Psychol Health. 2016;31(2):184204. doi: 10.1080/08870446.2015.1088015. Epub 2015 Oct 8. PMID: 26359768.

13. Mills $\mathrm{M}$, Cortezzo DE. Moral Distress in the Neonatal Intensive Care Unit: What Is It, Why It Happens, and How We Can Address It. Front Pediatr. 2020 Sep 10;8:581. doi: 10.3389/fped.2020.00581. PMID: 33014949; PMCID: PMC7511509.

14. Wigert $H$, Dellenmark MB, Bry K. Strengths and weaknesses of parent-staff communication in the NICU: a survey assessment. BMC Pediatr. 2013 May 7;13:71. doi: 10.1186/1471-2431-13-71. PMID: 23651578; PMCID: PMC3651269.

15. Jameton A. Nursing Practice: the Ethical Issues. Prentice Hall, Englewood Cliffs, NJ. 1984.

16. Jameton A. Nursing ethics and the moral situation of the nurse. In Choices and Conflict (Friedman E. ed.), American Hospital Association, Chicago, III, 1992, pp. 101-109.

17. Fourie $C$. Who Is Experiencing What Kind of Moral Distress? Distinctions for Moving from a Narrow to a Broad Definition of Moral Distress. AMA J Ethics. 2017 Jun 1;19(6):578-584. doi: 10.1001/journalofethics.2017.19.6.nlit1-1706. PMID: 28644787.

18. Swetz KM, Burkle CM, Berge KH, Lanier WL. Ten common questions (and their answers) on medical futility. Mayo Clin Proc. 2014 Jul;89(7):943-59. doi: 10.1016/j.mayocp.2014.02.005. Epub 2014 Apr 13. PMID: 24726213.

19. 19. McDougall R, Gillam L, Spriggs $M$, Delany $C$. The zone of parental discretion and the complexity of paediatrics: A response to Alderson. Clin Ethics. 2018 Dec;13(4):172-174. doi: 10.1177/1477750918789998. Epub 2018 Jul 25. PMID: 30568545; PMCID: PMC6243477.

20. Osborne A, Fish R, C Voos K. Antenatal counseling in the gray zone of viability. J Perinatol. 2020 Dec;40(12):1797-1801. doi: 10.1038/s41372-020-00818-5. Epub 2020 Oct 6. PMID: 33024254.

21. Foe G, Hellmann J, Greenberg RA. Parental Moral Distress and Moral Schism in the Neonatal ICU. J Bioeth Inq. 2018 Sep;15(3):319-325. doi: 10.1007/s11673-018-9858-5. Epub 2018 May 25. PMID: 29802588.

22. Campbell SM, Ulrich CM and Grady C. A broader understanding of moral distress. Am J Bioeth 2006; 16(12): 2-9.

23. Sydnor-Greenberg N, Dokken D. Coping and caring in different ways: understanding and meaningful involvement. Pediatr Nurs. 2000 Mar-Apr;26(2):185-90. PMID: 12026274.

24. Blencowe H, Cousens S, Oestergaard MZ, Chou D, Moller A-B, Narwal R, et al. National, regional, and worldwide estimates of preterm birth rates in the year 2010 with time trends since 1990 for selected countries: a systematic analysis and implications. Lancet. 2012;379(9832): 2162-72. 
25. Liu L, Johnson H, Cousens S, Perin J, Scott S, Lawn J, et al. Child Health Epidemiology Reference Group of WHO and UNICEF Global, regional, and national causes of child mortality: an updated systematic analysis for 2010 with time trends since 2000. Lancet. 2012;379(9832): 2151-61.

26. Prentice T, Janvier A, Gillam L, Davis PG. Moral distress within neonatal and paediatric intensive care units: a systematic review. Arch Dis Child. 2016 Aug;101(8):701-8. doi: 10.1136/archdischild-2015309410. Epub 2016 Jan 22. PMID: 26801075.

27. Gibbs G. The Sage qualitative research kit. Analyzing qualitative data. Sage Publications Ltd. 2007.

28. Burnard P, Gill P, Stewart K, Treasure E, Chadwick B. Analysing and presenting qualitative data. $\mathrm{Br}$ Dent J. 2008; 204(8): 429-432.

29. Patton MQ. Two Decades of Developments in Qualitative Inquiry: A Personal, Experiential Perspective. Qualitative Social Work 2002; 1(3): 261-283.

30. Sneath N. Discharge teaching in the NICU: are parents prepared? An integrative review of parents' perceptions. Neonatal Network. 2009;28(4): 237-46.

31. Raines D. Preparing for NICU Discharge: Mothers' Concerns. Neonatal Netw. 2013;32(6):399-403.

32. Verberne LM, Kars MC, Schouten-van Meeteren AY, et al. Aims and tasks in parental caregiving for children receiving palliative care at home: a qualitative study. Eur J Pediatr 2017; 176(3): 343-354.

33. Aarthun A, Øymar KA, Akerjordet K. Parental involvement in decision-making about their child's health care at the hospital. Nurs Open. 2018;6(1):50-58. Published 2018 Jul 30. doi:10.1002/nop2.180

34. Greene MM, Rossman B, Patra K, Kratovil A, Khan S, Meier PP. Maternal psychological distress and visitation to the neonatal intensive care unit. Acta Paediatr. 2015 Jul;104(7):e306-13. doi: 10.1111/apa.12975. Epub 2015 Feb 27. PMID: 25684177; PMCID: PMC4792263.

35. Harris R, Gibbs D, Mangin-Heimos K, Pineda R. Maternal mental health during the neonatal period: Relationships to the occupation of parenting. Early Hum Dev. 2018 May;120:31-39. doi: 10.1016/j.earlhumdev.2018.03.009. Epub 2018 Apr 4. PMID: $29625369 ;$ PMCID: PMC5951762.

36. Gonya J, Nelin LD. Factors associated with maternal visitation and participation in skin-to-skin care in al all referral level IIIc NICU. Acta Paediatr. 2013; 102:53-6. [PubMed: 23113613]

37. Rossman B, Greene MM, Kratovil AL, Meier PP. Resilience in Mothers of Very-Low-Birth-Weight Infants Hospitalized in the NICU. J Obstet Gynecol Neonatal Nurs. 2017 May-Jun;46(3):434-445. doi: 10.1016/j.jogn.2016.11.016. Epub 2017 Mar 2. PMID: 28263724.

38. Stelwagen M, van Kempen A, Westmaas A, Vet E, Scheele F. Parents' Experiences With a Model of Integrated Maternity and Neonatal Care Designed to Empower Parents. J Obstet Gynecol Neonatal Nurs. 2021 Mar;50(2):181-192. doi: 10.1016/j.jogn.2020.11.001. Epub 2021 Jan 8. PMID: 33428875.

39. Serpero LD, Sabatini M, Colivicchi M, Gazzolo D. Rooming-in: an update. Early Human Dev. 2013;89: S12-S4.

40. Lester BM, Hawes K, Abar B, Sullivan M, Miller R, Bigsby R, et al. Single-Family Room Care and Neurobehavioral and Medical Outcomes in Preterm Infants. Pediatrics. 2014;134(4): 754-60. 
41. Garfield CF, Lee Y, Kim HN. Paternal and Maternal Concerns for Their Very Low-Birth-Weight Infants Transitioning From the NICU to Home. J Perinat Neonatal Nurs. 2014;28(4): 305-12.

42. Aagaard H, Uhrenfeldt L, Spliid M, Fegran L. Parents' experiences of transition when their infants are discharged from the Neonatal Intensive Care Unit: a systematic review protocol. JBI Database System Rev Implement Rep. 2015 Oct;13(10):123-32. doi: 10.11124/jbisrir-2015-2287. PMID: 26571288.

43. Staver MA, Moore TA, Hanna KM. An integrative review of maternal distress during neonatal intensive care hospitalization. Arch Womens Ment Health. 2021 Apr;24(2):217-229. doi: 10.1007/s00737-020-01063-7. Epub 2020 Aug 27. PMID: 32851469.

44. Barnum B. Benevolent injustice: a neonatal dilemma. Adv Neonatal Care. 2009 Jun;9(3):132-6. doi: 10.1097/ANC.0b013e3181a72d19. PMID: 19542777.

45. Hamric A and Epstein EG. A health system-wide moral distress consultation service: development and evaluation. HEC Forum 2017; 29(2): 127-143.

46. Prentice TM, Gillam L, Davis PG, Janvier A. The use and misuse of moral distress in neonatology. Semin Fetal Neonatal Med. 2018 Feb;23(1):39-43. doi: 10.1016/j.siny.2017.09.007. Epub 2017 Sep 28. PMID: 28964686.

47. Wilkinson D. Who should decide for critically ill neonates and how? The grey zone in neonatal treatment decisions. In: McDougall R, Delany C, Gillam L, editors. When Doctors and Parents Disagree: Ethics, Paediatrics \& the Zone of Parental Discretion. Sydney (AU): The Federation Press; 2016 Jun 20. Chapter 4. PMID: 28661627.

48. Gillam L. The zone of parental discretion: An ethical tool for dealing with disagreement between parents and doctors about medical treatment for a child. Clinical Ethics. 2016;11(1):1-8.

49. Janvier A, Nadeau S, Deschênes M, Couture E, Barrington KJ. Moral distress in the neonatal intensive care unit: caregiver's experience. J Perinatol. 2007 Apr;27(4):203-8. doi: 10.1038/sj.jp.7211658. Epub 2007 Feb 15. PMID: 17304208. 